\title{
Determining the Efficiency and Yield of Caffeine Extraction for Robusta and Arabica Coffee Beans
}

\author{
Zeyu Yu ${ }^{1}$, Akshay Jakkidi Reddy ${ }^{1}$, Himanshu Wagh ${ }^{2}$ \\ ${ }^{1}$ California Northstate University College of Health Sciences, Rancho Cordova, USA \\ ${ }^{2}$ California Northstate University College of Medicine, Elk Grove, USA
}

*Corresponding author: Himanshu Wagh, California Northstate University College of Medicine, Elk Grove, USA, Email: Himanshu.wagh5630@cnsu.edu

\begin{abstract}
The objective of this review is to determine the difference in caffeine content in the coffee beans from different brands that are available in Costco. Two different popular coffee bean brands were bought and tested to determine which brand would have the highest caffeine content and their relative popularity among consumers. The extraction DMC method was conducted by using chemicals such as calcium carbonate, water, and DMC. The same amount of coffee beans were boiled with water until highly concentrated solutions were formed. Extraction funnel was utilized to wash out caffeine. Then, the recrystallization and vacuum filtration was utilized to obtain caffeine in solid form. The identity of the product along with the purity of the product was determined using melting temp, IR-spectroscopy, UV-vis spectrum, and TLC plating. The mass of caffeine produced from individual coffee brands were measured and compared. It was hypothesized that robusta coffee beans would yield more caffeine than arabica coffee beans. The expected results verify those claims as the data demonstrates that the amount of caffeine extracted from 10 grams of robusta coffee would be around .8021 grams, while the amount of caffeine extracted from 10 grams of arabica coffee would be around .4321 grams. The IR graph, UV-vis graph, and TLC plate were conducted to verify the identity of the product. The predicted IR graph, UV-vis graph, and TLC plate closely matched with the literature values, which indicates that the product produced is pure caffeine. One source of error that could skew the data could be the presence of impurities from the coffee beans that react in solution while we are trying to extract the caffeine. The broader impact of this review is that by understanding the caffeine content in different products, the medical and scientific field can further determine the difference in health effects between excess and optimal caffeine consumption to the human body. Additionally, scientists can research various medical usages of caffeine to help different patients with sleep disorders.
\end{abstract}

Keywords Caffeine

\section{INTRODUCTION}

Coffee has been embedded in Americans' daily life for the past few decades. On average, American adults that are within the age range of 20-34 years old drink up to $5 \mathrm{mg}$ of caffeine each day [1]. Although caffeine has adverse effects on human health such as increased blood pressure [2], many people still choose to drink the beverage. Some drink for taste while some drink for the caffeine that gives them a biological boost that fuels 


\section{Research Article}

their entire day. However, the amount of money that people spend varies depending on their socioeconomic status and their objectives. Furthermore, some people might be given such a perception that a more expensive type of coffee bean would demonstrate better effects in generating more caffeine, giving the drinkers more fuel for the day. Therefore, this research is called to investigate if price correlates with the amount of caffeine produced by various coffee beans. The hypothesis for this lab experience is that there is no correlation between the price of the coffee beans and the amount of caffeine in the coffee beans. This is because caffeine beans can only produce a certain amount of caffeine and will plateau at a certain point. This is also due to the fact that the type of coffee bean is thought to have. Therefore, there should be no correlation between price and the amount of caffeine in the coffee beans. Arabica coffee beans have been known to have a caffeine $\left(\mathrm{C}_{8} \mathrm{H}_{10} \mathrm{~N}_{4} \mathrm{O}_{2}\right)$ composition of .9 to $1.3 \%$ per coffee bean, while robusta coffee beans have been known to have a caffeine composition of 1.51 to $3.33 \%$ per coffee bean [3]. Boiling the raw coffee beans will allow scientists to concentrate the caffeine content. This investigation compares the caffeine content in the arabica coffee beans from Costco to the caffeine content of robusta and liberica coffee beans bought from other sources. The extraction process took place under high pressures as this is extremely inefficient for extracting caffeine from coffee [4]. Lastly, IR spectrometer, UVvis spectrum, and computation via Avogradro's systems were utilized to determine the identity of the substance. The broader impact of this study is that it will hopefully raise awareness of caffeine consumption within the general population as this study should help to determine the amount of caffeine present in each individual brand of coffee beans.

\section{DATA}

\section{Scheme 1}

Each Arabica coffee beans has $6 \mathrm{mg}$ of caffeine and each arabica coffee is about 0.12 gram

Robusta coffee beans have about 2.2 percent of caffeine by weight or twice as much of Arabica coffee bean
Theoretical Yield of caffeine from Arabica coffee beans: $10 \mathrm{~g} / 0.12 \mathrm{~g}=83.3$ Arabica Coffee Beans $83.3 \times 0.006=0.4998$ gram of $\mathrm{C}_{8} \mathrm{H}_{10} \mathrm{~N}_{4} \mathrm{O}_{2}$

Theoretical Yield of caffeine from 0.4998 Robusta coffee beans: 0.4998 grams x $2=1$ gram of $\mathrm{C}_{8} \mathrm{H}_{10} \mathrm{~N}_{4} \mathrm{O}_{2}$

\begin{tabular}{|l|c|}
\hline Table 3: TLC Plating and Rf values \\
\hline Source of Caffeine & *Expected Rf \\
\hline Arabica coffee beans & 0.71 \\
\hline Robusta coffee beans & 0.73 \\
\hline Theoretical(literature) Coffee & 0.64 \\
\hline
\end{tabular}

\section{DISCUSSION}

Table 1 demonstrates the predicted melting temperature of the product $\mathrm{C}_{8} \mathrm{H}_{10} \mathrm{~N}_{4} \mathrm{O}_{2}$

(caffeine) from both sources of coffee [7]. To distinguish the difference between the robusta and the arabica coffee, Table 2 was made to identify the amount of caffeine produced by both brands of coffee [8]. From Table 3, it was determined that both predicted products from both coffee were more nonpolar than the literature product [9]. The slight difference between the predicted $\mathrm{Rf}$ values $(0.71$ and 0.73$)$ compared to the literature Rf value (0.64) might indicate potential impurity within the product sample. This can be due to different errors such as equipment contamination, imprecise extraction method, and random errors due to measurement along with calculation inaccuracy. Figures 1,3, and 4 had peaks around $1700 \mathrm{~cm}^{-1}$ and $1500 \mathrm{~cm}^{-1}$ which indicates that the product that was collected from both the robusta and the arabica coffee was relatively pure as caffeine should have peaks around those regions as the caffeine molecule has aromatic double bonds as well as carbonyl groups [10]. Alkane and Alkene stretches were also identified around $3100 \mathrm{~cm}^{-1}$ and $2900 \mathrm{~cm}^{-1}$ in both of the predicted IR graphs for the caffeine product. From Figure 2, the predicted UV-vis spectrum graph, the peak wavelength on the graphs was around $280 \mathrm{~nm}$, which indicated the presence of a carbonyl group [11]. This structural composition closely matched the literature UV-vis spectrum for caffeine. The

Table 1: Predicted Melting Temperature of Caffeine.

\begin{tabular}{|l|c|c|c|c|}
\hline Melting Temp & Trial 1 $\left({ }^{\circ} \mathbf{C}\right)$ & Trial 2 $\left({ }^{\circ} \mathbf{C}\right)$ & Literature $\left({ }^{\circ} \mathbf{C}\right)$ & Percent Error $\left({ }^{\circ} \%\right)$ \\
\hline $\mathbf{C}_{\mathbf{8}} \mathbf{H}_{10} \mathbf{N}_{4} \mathbf{O}_{\mathbf{2}}$ from Arabica Coffee Beans & $225-227$ & $226-229$ & $227-228$ & $0.88 \%$ \\
\hline $\mathbf{C}_{\mathbf{8}} \mathbf{H}_{10} \mathbf{N}_{4} \mathbf{O}_{\mathbf{2}}$ from Robusta Coffee Beans & $225-228$ & $224-227$ & $227-228$ & $1.10 \%$ \\
\hline
\end{tabular}

Table 2: Percent Yield of Caffeine.

\begin{tabular}{|l|c|c|c|}
\hline Product & Experimental Yield & Theoretical Yield & Percent Yield \\
\hline $\mathbf{C}_{\mathbf{8}} \mathbf{H}_{10} \mathbf{N}_{\mathbf{4}} \mathbf{O}_{\mathbf{2}}$ from Arabica Coffee Beans & 0.4321 grams & 0.4998 grams & $86 \%$ \\
\hline $\mathbf{C}_{\mathbf{8}} \mathbf{H}_{10} \mathbf{N}_{\mathbf{4}} \mathbf{O}_{\mathbf{2}}$ from Robusta Coffee Beans & 0.8021 grams & 1 gram & $80 \%$ \\
\hline
\end{tabular}




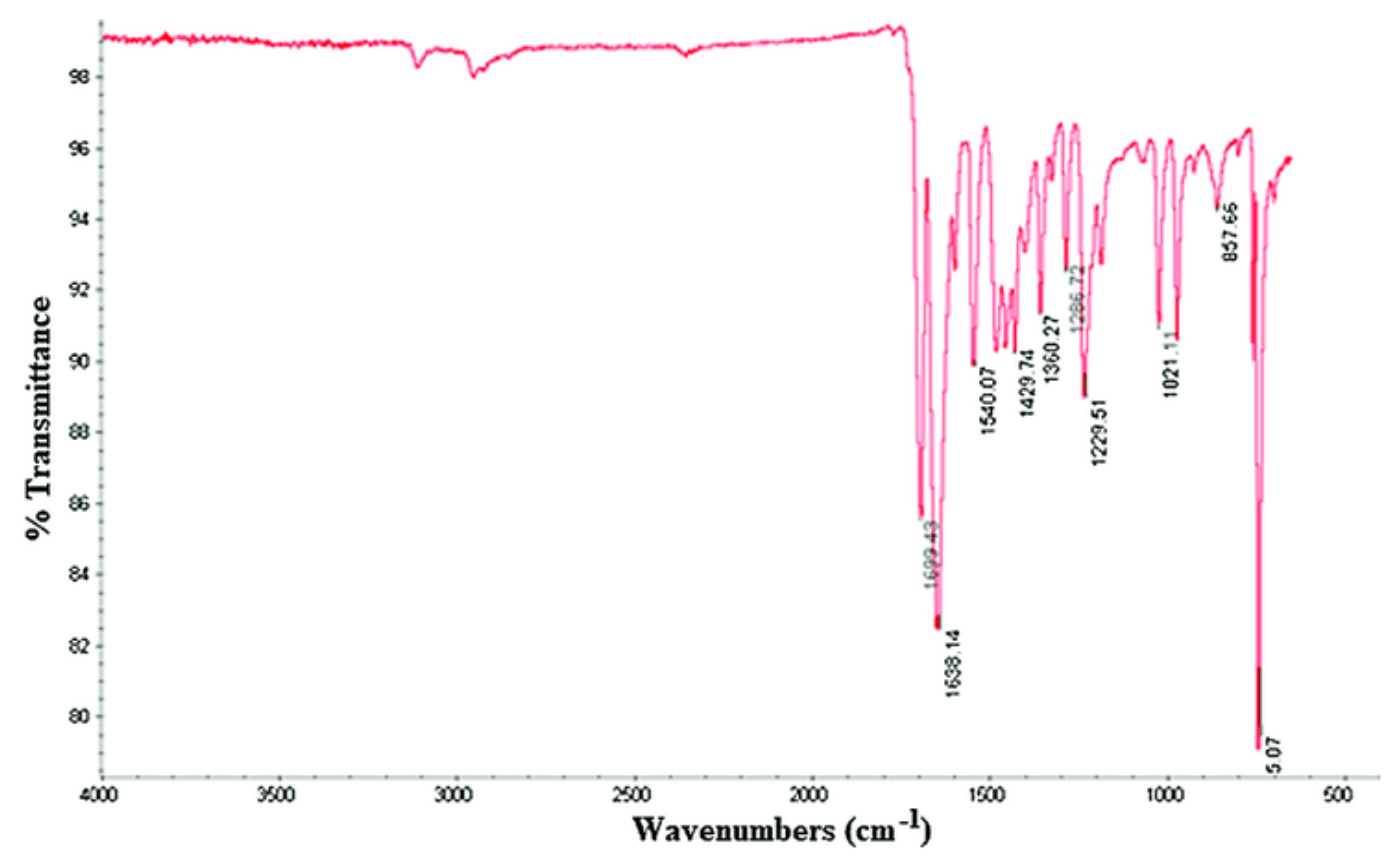

Figure 1: Literature IR Spectroscopy for $\mathrm{C}_{8} \mathrm{H}_{10} \mathrm{~N}_{4} \mathrm{O}_{2}$.

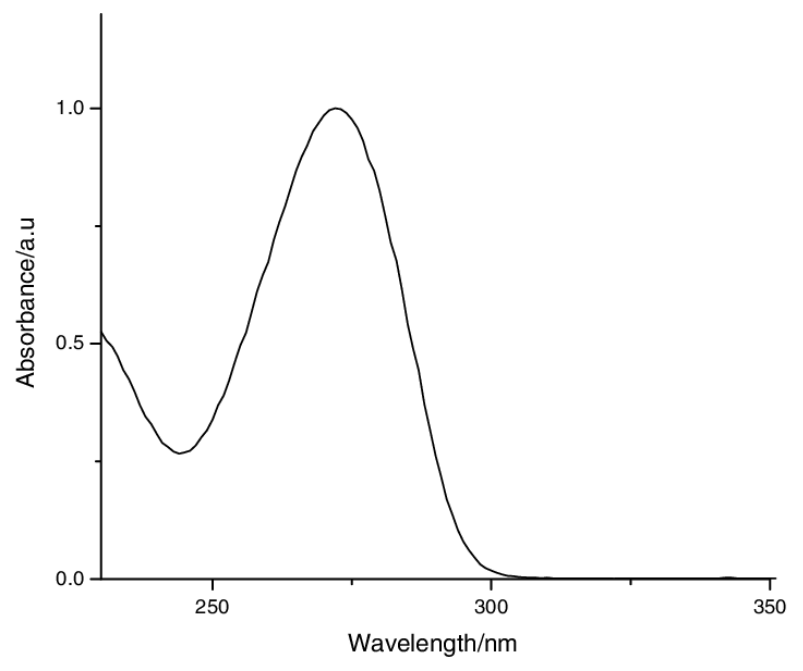

Figure 2: Literature UV-vis Spectrum for $\mathrm{C}_{8} \mathrm{H}_{10} \mathrm{~N}_{4} \mathrm{O}_{2}$.

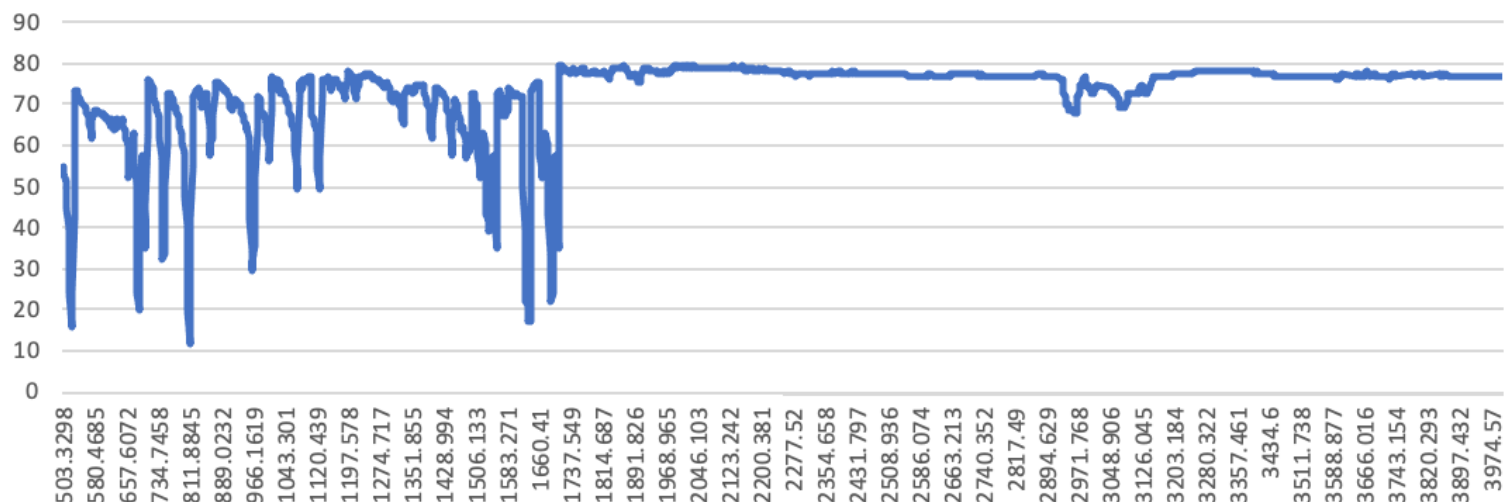

Figure 3: Predicted IR Spectroscopy for $\mathrm{C}_{8} \mathrm{H}_{10} \mathrm{~N}_{4} \mathrm{O}_{2}$ from Arabica coffee beans 


\section{Research Article}

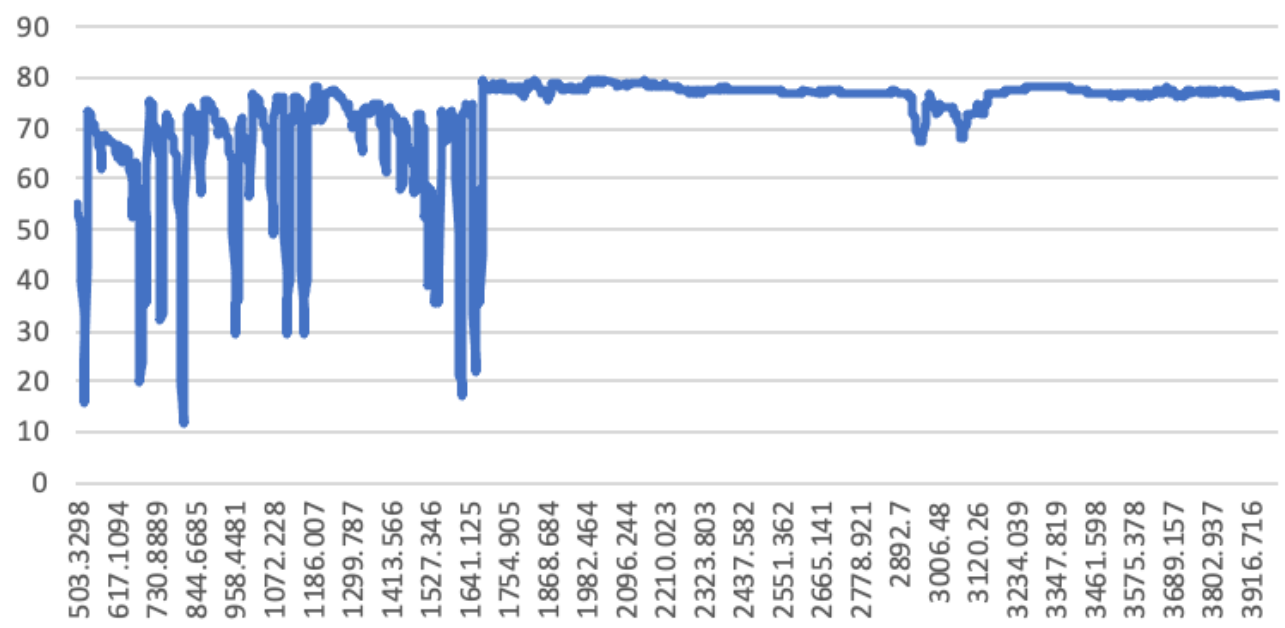

Figure 4: Predicted IR Spectroscopy for $\mathrm{C}_{8} \mathrm{H}_{10} \mathrm{~N}_{4} \mathrm{O}_{2}$ for Robusta coffee beans.

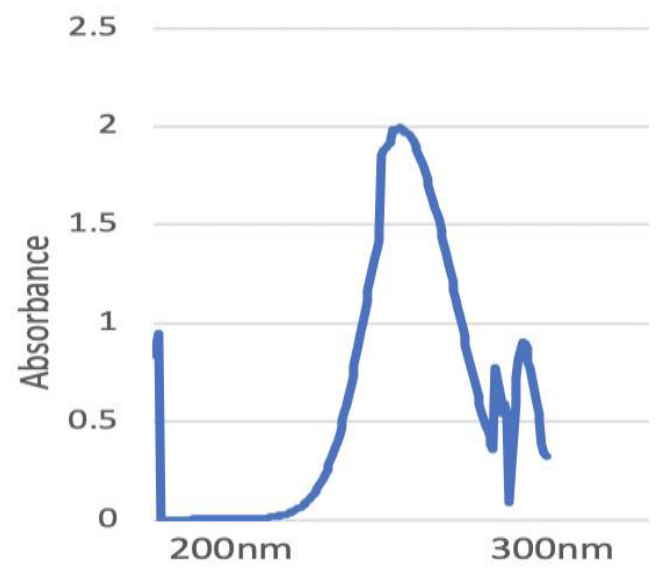

Figure 5: Predicted UV-vis Spectrum for $\mathrm{C}_{8} \mathrm{H}_{10} \mathrm{~N}_{4} \mathrm{O}_{2}$ for Arabica coffee beans.

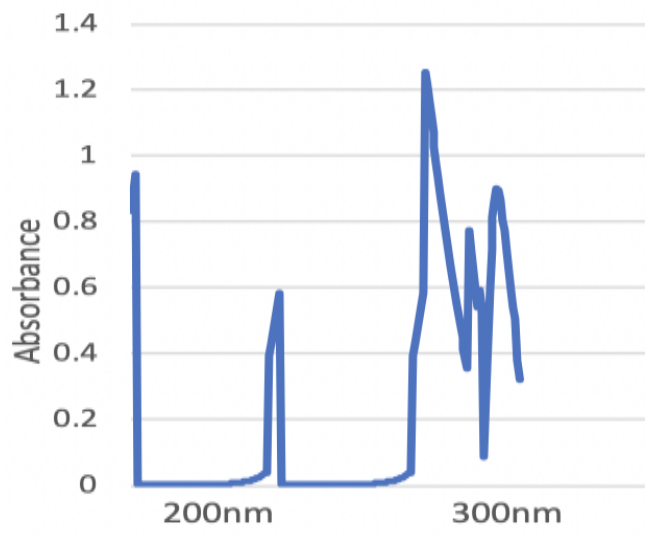

Figure 6: Predicted UV-vis Spectrum for $\mathrm{C}_{8} \mathrm{H}_{10} \mathrm{~N}_{4} \mathrm{O}_{2}$ from Robusta coffee beans. caffeine molecule has several carbonyl carbons. Therefore it can be deduced from both the UV-vis and IR data that the product that was collected was relatively pure .

The percent error is relatively low when comparing the predicted to the literature melting temperature. This is because the products are relatively pure and concentrated. The average melting temperature of caffeine from arabica coffee beans is $227-228^{\circ} \mathrm{C}$. The caffeine that was extracted from the robusta coffee beans demonstrated an average melting temperature of $226-228{ }^{\circ} \mathrm{C}$ [12]. The products had a slightly cooler melting temperature than what was expected, which can potentially indicate there are contaminations or impurity in the experimental sample. The source of error can be due to equipment contamination or procedural mistakes along the lab experiment. The caffeine that was extracted from the robusta coffee beans had an average melting temperature around $226^{\circ} \mathrm{C}$. This is slightly cooler than the expected melting temperature, which can potentially indicate there are contaminations or impurity in the experimental sample. However, because the difference in temperature is extremely small the error could also be attributed to inconsities of the melting point apparatus that was used to determine these values experimentally.

Lastly, $\mathrm{C}=\mathrm{O}$ ketone stretch was identified for the predicted IR graph and the literature graph [13]. Those stretches from the predicted graph closely matched the literature caffeine IR graph. This indicated that the product is relatively pure caffeine. This statement is additionally supported by the data that was collected. From the melting temp, IR-graphs, and UV-vis spectrum graph, it was determined that the product produced from the experiment is pure caffeine [14]. To further confirm the relative purity of product caffeine to the literature pure caffeine, a predicted TLC plate is done to compare the 
purity of predicted product and literature product. Scheme 1 was done to calculate the potential amount of caffeine produced by 10 grams of robusta and the arabica coffee. Literature values, such as how many grams of caffeine can be produced by a single coffee bean. Theoretical yield is further determined by calculating the exact caffeine amount that can be produced by 10 grams of coffee beans. From a literature source, it was determined that robusta coffee beans would produce twice as much caffeine than arabica coffee beans Therefore, the predicted yield of caffeine for robusta coffee beans (0.8021grams) would be about twice as much as the arabica coffee beans ( 0.4321 grams) [15]. The percent yield of robusta coffee is about 80 percent while 86 percent for arabica coffee beans. The percent yield is medium and this could be due to a few errors happening throughout the lab such as the product was not able to be entirely extracted, a loss of product through vacuum filtration, a loss of product in the solution dissolving process, calculation mistakes, broken or contaminated equipment, and not being able to fully follow the protocol. However, this indicates that the extraction method is relatively efficient as the percent yield is around 80 percent.

In comparing the two brands of coffee, it was determined that both brands of coffee (arabica and robusta) produce coffee with relatively similar purity. However, robusta coffee produces twice as much caffeine than arabica. This corresponds to the hypothesis as it is expected for robusta coffee to produce more caffeine. Although we were able to confirm our hypothesis, further research, maybe in the form of case reports, is needed in order to determine more about the effects of caffeine on the human body [16] Perhaps in the future AI software could also be used to help identify individuals who are addicted to caffeine and alleviate their symptoms [17-23]. Current literature may give us a decent understanding about the effects of caffeine, however additional research should still be conducted to verify those results [24].

\section{CONCLUSION}

This review demonstrated that the dichloromethane method was an efficient and reliable method of extracting caffeine from coffee beans. This method produced high yielding products from both brands of coffee beans, which reflects that this method can quickly produce analysis and observation. The IR and UV-vis spectrum graphs confirmed the identity of the product to be pure caffeine. The analysis of the TLC and melting point were indicative of a moderately reliable caffeine product, with some impurities, with both arabic and robusta coffee beans demonstrating a higher polarity in TLC and lower temperature in melting temperature. The impurities are likely a result of the additional chemical that is added into the coffee beans to artificially flavor the taste of the coffee. Calcium carbonate along with contamination in the equipment could be another source of error which they combined in the coffee solution, causing impurities within the caffeine. Nevertheless, further research is needed to ascertain more information about the effects that caffeine can have on the human body.

\section{ACKNOWLEDGEMENT}

We would like to thank Kara for her advising and additional perspectives on the project.

\section{REFERENCES}

1. Caporaso N, Whitworth MB, Grebby S, Fisk ID. Non-Destructive Analysis of Sucrose, Caffeine and Trigonelline on Single Green Coffee Beans by Hyperspectral Imaging. Food Research International 2018, 106, 193-203.

2. Drewnowski A, Rehm C. Sources of Caffeine in Diets of US Children and Adults: Trends by Beverage Type and Purchase Location. Nutrients 2016, 8 (3), 154.

3. Temple, J. L, Bernard, C, Lipshultz, S. E, Czachor, J. D, Westphal, J. A, Mestre, M. A. The Safety of Ingested Caffeine: A Comprehensive Review. Frontiers in Psychiatry 2017, 8.

4. Ilgaz S, Sat IG, Polat A. Effects of Processing Parameters on the Caffeine Extraction Yield during Decaffeination of Black Tea Using Pilot-Scale Supercritical Carbon Dioxide Extraction Technique. Journal of Food Science and Technology 2018, 55 (4), 1407-1415.

5. Aguilar-Navarro M, Muñoz G, Salinero J, Muñoz-Guerra J, Fernández-Álvarez M, Plata M, Coso JD. Urine Caffeine Concentration in Doping Control Samples from 2004 to 2015. Nutrients 2019, 11(2), 286.

6. Lisko JG, Lee GE, Kimbrell JB, Rybak ME, Valentin-Blasini L, Watson CH. Caffeine Concentrations in Coffee, Tea, Chocolate, and Energy Drink Flavored E-Liquids. Nicotine \& Tobacco Research 2016.

7. Reyes C, Cornelis M. Caffeine in the Diet: Country-Level Consumption and Guidelines. Nutrients 2018, 10(11), 1772.

8. Tytell M, Robinson M. Faculty of 1000 Evaluation for Coffee Extract and Caffeine Enhance the Heat Shock Response and Promote Proteostasis in an HSF-1-Dependent Manner in Caenorhabditis Elegans. F1000 - Post-publication peer review of the biomedical literature 2017.

9. Ocallaghan F, Muurlink O, Reid N. Effects of Caffeine on Sleep Quality and Daytime Functioning. Risk Management and Healthcare Policy 2018, Volume 11, 263-271.

10. Willson, C. The Clinical Toxicology of Caffeine: A Review and Case Study. Toxicology Reports 2018, 5, 1140-1152.

11. Fuller M, Rao NZ. The Effect of Time, Roasting Temperature, and Grind Size on Caffeine and Chlorogenic Acid Concentrations in Cold Brew Coffee. Scientific Reports 2017, 7 (1), 1-7. 


\section{Research Article}

12. Li QR, Wu M, Huang RJ, Chen YF, Chen CJ, Li H, Ni H, Li HH. Extraction and Preparation of High-Aroma and Low-Caffeine Instant Green Teas by the Novel Column Chromatographic Extraction Method with Gradient Elution. Journal of Food Science and Technology 2017, 54 (7), 2186-2192.

13. Banerjee S, Chatterjee J. Efficient Extraction Strategies of Tea (Camellia Sinensis) Biomolecules. Journal of Food Science and Technology 2014, 3158-3168.

14. Cordoba N, Pataquiva L, Osorio C, Moreno FLM, RuizRY. Effect of Grinding, Extraction Time and Type of Coffee on the Physicochemical and Flavour Characteristics of Cold Brew Coffee. Scientific Reports 2019, 9 (1).

15. Naviglio, Scarano, Ciaravolo, Gallo. Rapid Solid-Liquid Dynamic Extraction (RSLDE): A Powerful and Greener Alternative to the Latest Solid-Liquid Extraction Techniques. Foods 2019, 8 (7), 245.

16. Reddy AJ, Tak N, Martel JB. Case study of endogenous streptococcal endophthalmitis in the critical care setting. Cureus. 2021, 5:e16192. 10.7759/cureus.16192

17. Tak N, Reddy AJ, Martel J, et al. Clinical Wide-Field Retinal Image Deep Learning Classification of Exudative and NonExudative Age-Related Macular Degeneration. Cureus 13(8): e17579. doi:10.7759/cureus. 17579

18. Reddy AJ, Martel JB: Deep neural network learning for detection and grading of diabetic retinopathy. Appl Cell. 2020, 8:67-73. 10.53043/2320-1991.acb90001
19. Senthilraja V, Lou E, Nakka A, Karamian P, Aslam I, Rabara J, Gahoonia N, Kaur N, Reddy A, Ber T, Wagh H (2021). Exploring drug and antibody-based treatment options for creutzfeldtjakob disease. Applied Cell Biology, 9(2), 43-48. https://doi. org/10.53043/2320-1991.acb90008

20. Sunil A, Shaheed G, Reddy AJ, Nawathey N, Brahmbhatt H. A review on the role of ethylenediaminetetraacetic acid (EDTA) in the treatment and understanding of psoriasis. Cureus. 2021, 16:e16424. 10.7759/cureus. 16424

21. Wagh H, Reddy AJ: A comparison of DASH scores resulting from different treatment options for the intra-articular distal radius fracture in the geriatric population. Appl Cell Biol. 2021, 9:18-23. 10.53043/2320-1991.acb90004

22. Tak N, Wagh P, Sandhu S, Reddy A, Wagh H: A quantitative analysis on the effect of varying nitrate concentrations on $\mathrm{pH}$ levels on the growth of algae. Appl Cell Biol. 2021, 9:24-28. 10.53043/2320-1991.acb90005

23. Sandhu S, Sandhu A, Reddy AJ, Wagh H, et al. :An Investigative Study into the C. flumenia and its Interactions with its Surrounding Ecosystem. Appl Cell Biol. 2021, 9:33-42. 10.53043/2320-1991. acb90007

24. Blystone RV, Blodgett K. WWW: the scientific method. CBE Life Sci Educ. 2006 Spring;5(1):7-11. doi: 10.1187/cbe.05-120134 